\title{
MERCERIZATION EFFECT ON THE MECHANICAL AND PHYSICAL PROPERTIES OF BANANA FIBER POLYESTER COMPOSITE
}

\author{
Emekwisia Chukwudubem .C. \\ Department of Mechanical Engineering \\ University of Nigeria Nsukka, \\ Enugu-State, Nigeria.
}

\author{
Ezema Ikechukwu .C. \\ Department of Metallurgical and Materials \\ Engineering, University of Nigeria, \\ Enugu-State, Nigeria.
}

\author{
Aigbodion Victor .S \\ Department of Metallurgical and Materials \\ Engineering, University of Nigeria, Nsukka, \\ Enugu-State, Nigeria.
}

Abstract- The surface modification of natural fiber is a major key in enhancing fiber properties. It aids to reduce certain weakness in the fiber such as poor surface adhesion to hydrophobic polymers, etc. Thus, in order to improve the properties of Banana Fruit Bunch Fiber (BFBF), sodium Hydroxide (Mercerization) was used to modify (treat) BFBF at constant concentration but at various treatment time (1-3hours). The result showed that maximum tensile strength and impact strength of the treated fiber were $7.918 \mathrm{MPa}$ and $82.184 \mathrm{j} / \mathrm{m}^{2}$, both at 3hours optimum soaking time, while their untreated gave $7.204 \mathrm{MPa}$ and $84.421 \mathrm{j} / \mathrm{m}^{2}$ respectively. The maximum flexural strength and modulus of the treated fiber gave 83.092MPa and 6416.54MPa, both at 1hour optimum soaking time, and their untreated were 30.515MPa and $3708.506 \mathrm{MPa}$ respectively. The maximum Bundle Fiber Tensile Strength and Water Absorption of the treated fiber was 30.648MPa and 3.379\%, both at 3hours and their untreated were $78.518 \mathrm{MPa}$ and $1.455 \%$ respectively. Also, the maximum density of the treated fiber was $1145.871 \mathrm{~g} / \mathrm{cm}^{3}$ at 2 hours, while the untreated gave $1099.860 \mathrm{~g} / \mathrm{cm}^{3}$. The method used for composite preparation is Hand Lay-up method. The SEM result showed a better fibermatrix surface adhesion of the treated fiber than the untreated. The TGA/DTA results showed improvement in the thermal stability of the composite at $450^{\circ} \mathrm{C}$. The XRD test also showed greater percentage crystallinity of the fibers. These results showed that $\mathrm{NaOH}$ treatment improved the property of banana fibers at different optimum soaking time. Thus, it is established that alkali treatment can be used for the improvement of the properties of Banana fibers for industrial applications.

Keywords- Banana Fruit Bunch Fiber (BFBF), Sodium Hydroxide (NaOH), Scanning Electron Microscope (SEM), Thermo-gravimetric Analysis (TGA), X-Ray Diffraction(XRD).

\section{INTRODUCTION}

NATURAL fibers are used in making fiber composite due to their light weight, excellent strength to weight ratios, resistance to corrosion, easy to fabricate, design flexibility, self-lubricating properties, better coefficient of friction, wear resistance and high durability. These fiber properties make them attractive materials as compared to others and as such can therefore be applied in the production of engineering objects and components such as panels for false ceiling, particle boards, wall, floor, window and door frames, roof tiles, chair, table, bath units, suitcases, helmets, etc. Fiber reinforced composites are composed of fibers and a matrix. Fibers are the reinforcement and the major source of strength. The matrix glues the fibers together in shape and transfers stresses between the reinforcing fibers. The fibers therefore carry the loads along their longitudinal directions. (Campbell, 2010) (Pilato, Louis A., Michno, no date) 


\section{International Journal of Engineering Applied Sciences and Technology, 2019 \\ Vol. 4, Issue 5, ISSN No. 2455-2143, Pages 124-132 \\ Published Online September 2019 in IJEAST (http://www.ijeast.com)}

The hydrophilic nature of natural fiber and the matrix been hydrophobic in nature, leads to poor adhesion of the fiber with the polymer matrix and further deteriorates the mechanical properties of the composites. (Sood and Dwivedi, 2018). In order to introduce compatibility between the natural fibers and the polymer matrix, natural fiber is modified and the effectiveness of interfacial adhesion is improved. Chemical modification of natural fiber exposes more reactive groups on the fiber surface and thus promotes more efficient coupling with polymer matrix. These modifications such as acetylation treatment, isocyanate treatment, maleated coupling agents, alkali treatment, silane coupling agents, and grafting have been conducted to improve fiber matrix adhesion. (Eng et al., 2014) .

(Arifuzzaman Khan et al., 2013) examined banana stem fiber by bleaching, alkalization, and acetylation, reinforced on maleic anhydride grafted polypropylene/low-density polyethylene composites. All the treated fibers exhibited better mechanical properties than the untreated ones. These were further supported by scanning electron microscopy images of the fracture surfaces.

(Ezema et al., 2012) chemically modified the banana stem and banana bunch fibers with the use of $\mathrm{Na}_{2} \mathrm{SO}_{3}$ and $\mathrm{NaOH}$ mixture. The ply tensile properties of the banana fiber reinforced natural rubber composite exhibited better mechanical properties than the unreinforced.

(J. Santhosh et al., 2014) showed that alkali treatment of banana fiber improved the mechanical properties of both the epoxy/vinyl ester and hybrid composite.

(Joseph, Koshy and Thomas, 2005) modified banana fiber using silane treatment, acetylation, cyanoethylation, latex treatment and $\mathrm{NaOH}$ (alkali), which improved the interfacial bonding with phenol formaldehyde (PF) resin. The mechanical properties performance of phenol formaldehyde composites reinforced with various treated fibers were found to be increased by all the modifications except latex treatment. Incorporation of heat treated, vinyl silane treated and acetylated fiber reinforced PF composites showed improvement in the impact strength of the PF fiber composites. These investigations showed that chemical modification of banana fiber had a better improvement in the fiber properties and proved a better result.

Thus, in this work, banana fiber was chemically modified by mercerization (Sodium Hydroxide) at various soaking time (1-3hours). The effect of these modifications on the mechanical and physical properties of banana fruit bunch fiber, reinforced in polyester composite was studied and compared with the untreated, in relation to the optimum soaking time. It therefore aimed at revealing the effect of soaking time of $\mathrm{NaOH}$ on the properties of BFBF reinforced polyester composite and obtain the best properties among them.

\section{MATERIALS AND METHODS.}

\section{A. Materials}

Banana Fruit Bunch Fiber (BFBF) was obtained from Nsukka Nigeria, as a waste material after the removal of the green back by water extraction (see Figure 1)

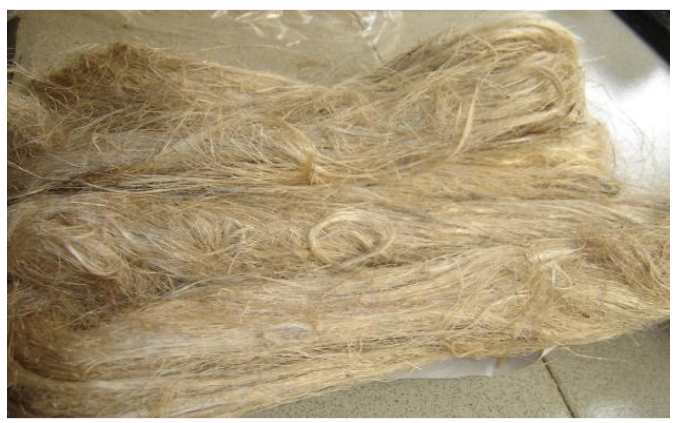

Fig. 1. Banana Fruit Bunch Fiber

The Sodium Hydroxide pellets were purchased from G.C. Obiorah chemical shop Ajasa-Nkpor, Anambra State, Nigeria. The unsaturated polyester resin with the corresponding catalyst (cobalt naphthalate) and accelerator (Methyl Ethyl Ketone Peroxide) were supplied by a vendor in Enugu state, Nigeria.

\section{B. Methods}

\section{Extraction of banana fiber}

Banana Fruit Bunch was cut into sections of 300$600 \mathrm{~mm}$ length. These sections were completely immersed in water for 14 days so as to promote the loosening of the fibers from the woody tissue (cellulose, hemi-cellulose and lignin), a process known as water retting. After which they were removed from the water and the fibers separated from the fruit bunch using hand method, washed thoroughly and sun-dried for 35hours. Some parts of the BFBF were further separated from the whole, weighed at 100gram respectively using the electronic weighing balance, for each treatment specimen.

\section{Preparation of the treatment agent}

By standard, 1mole (40gram) of Sodium hydroxide $(\mathrm{NaOH})$ pellets properly dissolves and reacts in $100 \mathrm{ml}$ of water (Murli and Harris, no date). Thus, the alkali solution was prepared as $600 \mathrm{ml}$ of water were reacted with 240gram of $\mathrm{NaOH}$, which produced 
sodium and hydroxide ion. During the reaction, lots of heats were emitted, showing the reaction to be exothermic. Thus, the equation is; $\mathrm{NaOH}+\mathrm{H}_{2} \mathrm{O} \rightarrow$ $\mathrm{Na}^{+}+\mathrm{OH}$. Therefore, 600ml of Aqueous Sodium hydroxide were therefore prepared for each treatment time.

\section{Sodium hydroxide Treatment.}

100gram of the BFBF were soaked in aqueous sodium hydroxide and allowed within the treatment time of 1 - 3hrs respectively. After which the treated BFBF was sun-dried for 60hours. The treated fibers were stretched and cut into a specific size of $50 \mathrm{~mm}$ since it has long fiber length, to enhance easy matting of the fiber. The treated fiber was matted using the conventional random mat method.

\section{Preparation of the composite}

The preparation method adopted in this work is the hand lay-up method. This method was used in fabricating the banana fiber composite. The fiber length used was $50 \mathrm{~mm}$. Unsaturated Polyester was used as matrix, and cobalt naphthenate and methyl ethyl ketone as catalyst and accelerator respectively. An Acrylic metal sheet coated with remover of size $300 \mathrm{~mm} \times 300 \mathrm{~mm} \times 10 \mathrm{~mm}$ dimensions is used as mould where the composite was poured into it. Using the roller, the liquid composite was pressed for proper spreading of resin and also voids minimization. Then the mould was allowed to cure for 24hours and post-cured for 240hours (10days) at room temperature.

\section{PROPERTIES}

\section{A. Tensile Strength}

The tensile test was performed with the aid of the Universal Testing Machine (UTM) (Model: M500$25 \mathrm{CT})$. The material was held by the grips and load is applied till failure occurs. Ultimate tensile test is noted and stress versus strain graph was generated. Three different types of samples were prepared for each test and the experiments carried out three times. The average (MPa) values were used for discussion. Test specimens were prepared into required dimension according to the dimensions, gauge length and cross head speeds of the testing instrument.

\section{B. Flexural Strength}

The Flexural Strength and modulus tests were done in a three-point flexural setup. The test specimen was cut according to the dimensions of the testing machine. The tests were carried out with the Universal Testing Machine (UTM). The test specimens were placed in the machine and force was applied to it until it fractures and breaks. The bending strength at peak was noted and stress vs. strain graphs was generated.

\section{Impact Strength}

The impact test specimens were prepared according to the required dimension of the testing instrument. During the testing process, the specimen was loaded in the testing machine and allows the pendulum until it fractures or breaks. The energy needed to break the material was noted and the impact strength was determined using the following equation;

$$
G_{c}=\frac{U}{A}\left(J / m^{2}\right)
$$

Where; $\mathrm{G}_{\mathrm{c}}=$ Impact strength; $\mathrm{U}=$ Energy of fracture (in joule); $\mathrm{A}=$ Cross section area $\left(\mathrm{inm}^{2}\right.$ )

\section{Bundle Fiber Tensile Test (BFTS)}

The BFTS was obtained by the Universal Testing Machine (UTM) and the graphs automatically generated. A valid test result was considered to be one in which fiber failure doesn't occur in the gripping region. This was done according to ASTM D 3822-01 for tensile strength. The treated and untreated banana fiber strands with length of about 1.5 times the gage length $(190 \mathrm{~mm})$ were separated. They were passed through a biro-pen orifice of 0.60 $\mathrm{mm}$ diameter till it filled the orifice and thereby formed a fiber bundle. The test method involved the use of carton paper tab for mounting the bundle fibers. The bulk fiber is laid across the cutout of the tab and attached using an adhesive. The tabs were mounted into a set of grips of a tensile testing machine and then the tabs were cut at mid-gage. For each test, a total of three samples were experimented and the average result determined.

\section{E. Water Absorption Test}

The composite samples were immersed in water at agreed upon conditions, often $23^{\circ} \mathrm{C}$ for 24 hours and removed at regular intervals (every 24hrs) up to 96$120 \mathrm{hrs}$, at which most specimens reached their saturation points. At each point of removal, the specimens are patted dry with a lint free cloth, and weighed. An electronic weighing balance was used to check the weight of water absorbed. The percentage water absorption (\%W.A) was determined with this expression;

$$
\% \mathrm{~W} . \mathrm{A}=\frac{\text { Wet weight }- \text { Dry weight }}{\text { Dry Weight }} \times 100
$$




\section{F. Density test}

The density of the composite $\rho_{c}$ was determined using this expression; $\rho_{c}=\rho_{f} V_{f}+\rho_{m} V_{m}$. First, the mass of fiber $\left(M_{f}\right)$ and that of matrix $\left(M_{m}\right)$ were found using an electronic balance, while the volume of matrix $\left(\mathrm{V}_{\mathrm{m}}\right)$ was determined using measuring cylinder. Secondly, the density of the matrix $\left(\rho_{m}\right)$ was determined using the equation for the density of a substance $\left(M_{m} / V_{m}\right)$. Then, the density of the fiber $\left(\rho_{f}\right)$ was determined with same equation for density, $M_{F} / V_{f}$. The volume of the fiber $\left(V_{f}\right)$ was determined with the aid of the Archimedes principle since it provides a convenient and accurate method for determining the volume of an irregularly shaped object. Kerosene was used as immersion liquid in line with (Edwards, 2014). Using this principle, the volume of the liquid (kerosene) displaced is equal to the volume of the fiber $\left(V_{k}=V_{f}\right)$. Hence, the fiber was submerged in the kerosene; some portion of the kerosene was displaced into a smaller bowl. The values were substituted into the expression for density of the composite, and the composite density determined.

\section{G. Scanning Electron Microscope (SEM)}

Fiber surface morphology analysis is important to ascertain the structural changes occurring in a fiber composite upon treatment. The Scanning Electron Microscope (SEM) result of the composites was determined with the use of TESCAN VEGA 3 SBU (2units).

\section{H. Thermogravimetric Analysis} (TGA)/Dynamic Thermal Analysis

The TGA/DTA of the fiber composite were conducted with the aid of a universal V4.5A TA Instruments for evaluating the thermal stability of the fibers, with weight percent between 0 to $120 \%$ and temperature range of 0 to $500^{\circ} \mathrm{C}$.

\section{X-Ray Diffraction}

The XRD tests of the fiber composite were performed with the use of an X-ray diffractometer. The diffraction intensity was between $0^{\circ}$ to $90^{\circ}$ at $2 \theta$ scale (Bragg angle) and at 1 second step time was applied with the intensities between 0 to 900 counts. Percentage Crystallinity (\%Cr.) and Crystalline Index (Cr.I) was calculated with the following expressions;

$$
C . I=\frac{I_{22}-I_{18}}{I_{22}} \text { and } \% C r=\frac{I_{22}}{I_{22}+I_{18}} \times 100
$$

Where $\mathrm{I}_{22}$ and $\mathrm{I}_{18}$ are the crystalline and amorphous intensities at $2 \theta$ scale close to $22^{\circ}$ and $18^{\circ}$, respectively. (K. Kaushik, Kumar and Kalia, 2013)

\section{RESULTS AND DISCUSSION}

A. Effect of Alkali soaking time on the mechanical properties of $\mathrm{BFBF} / \mathrm{Polyester}$ composite.

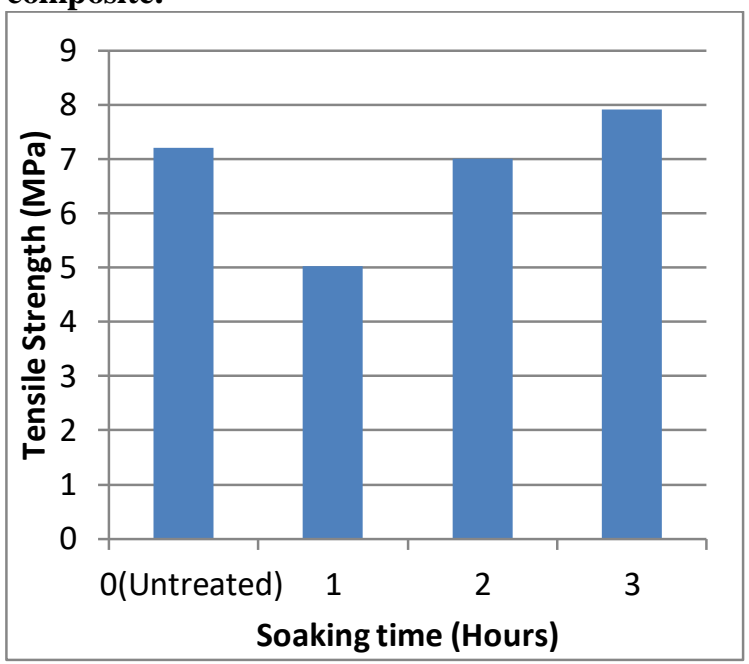

(a)

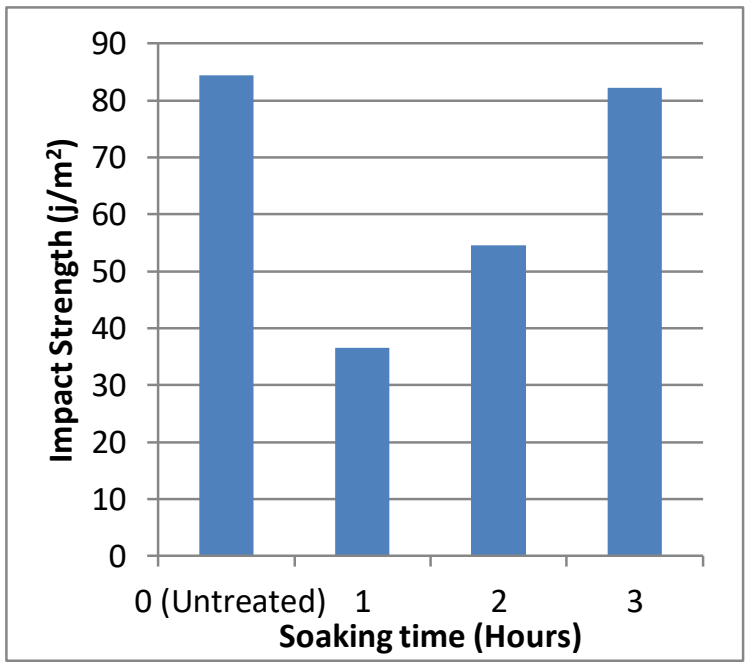

(b)

Fig. 2. (a) Tensile strength of treated and Untreated BFBF polymer composite.

(b) Impact strength of treated and untreated BFBF polyester composite. 


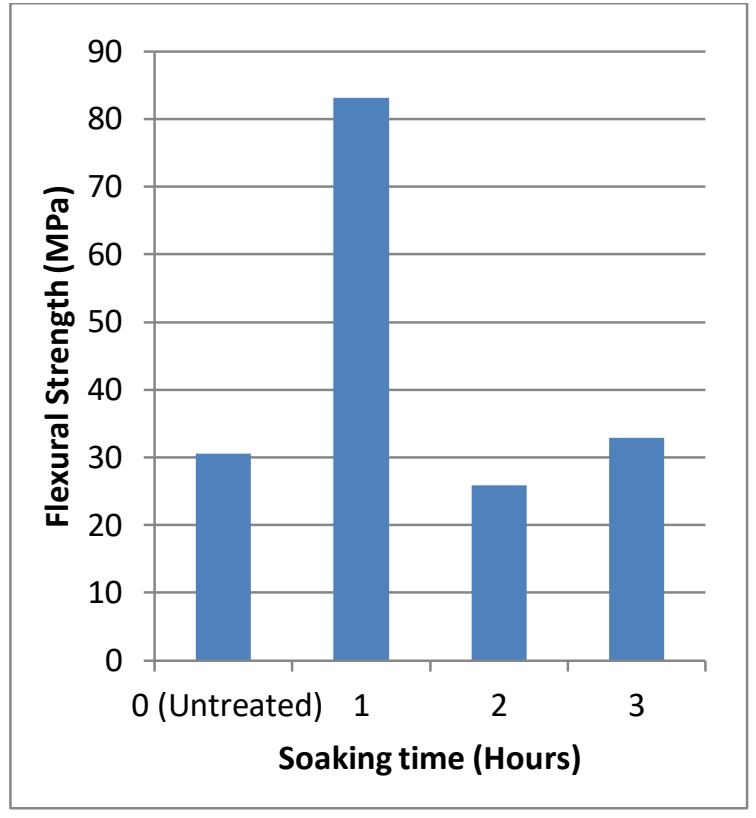

(a)

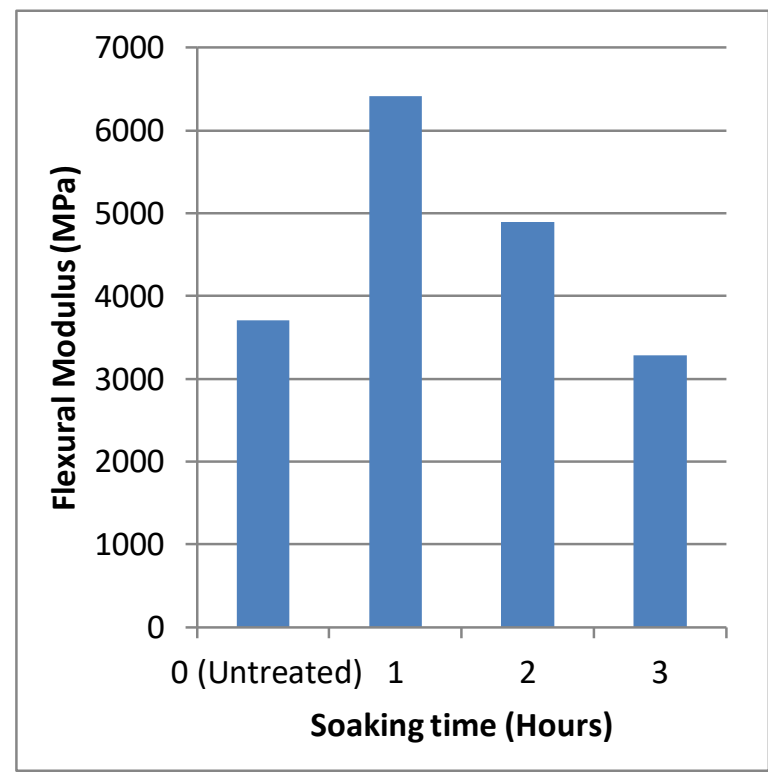

(b)

Fig. 3a. Flexural Strength of treated and untreated BFBF polyester composite.

Fig. 3b. Flexural Modulus of treated and untreated BFBF polyester composite.

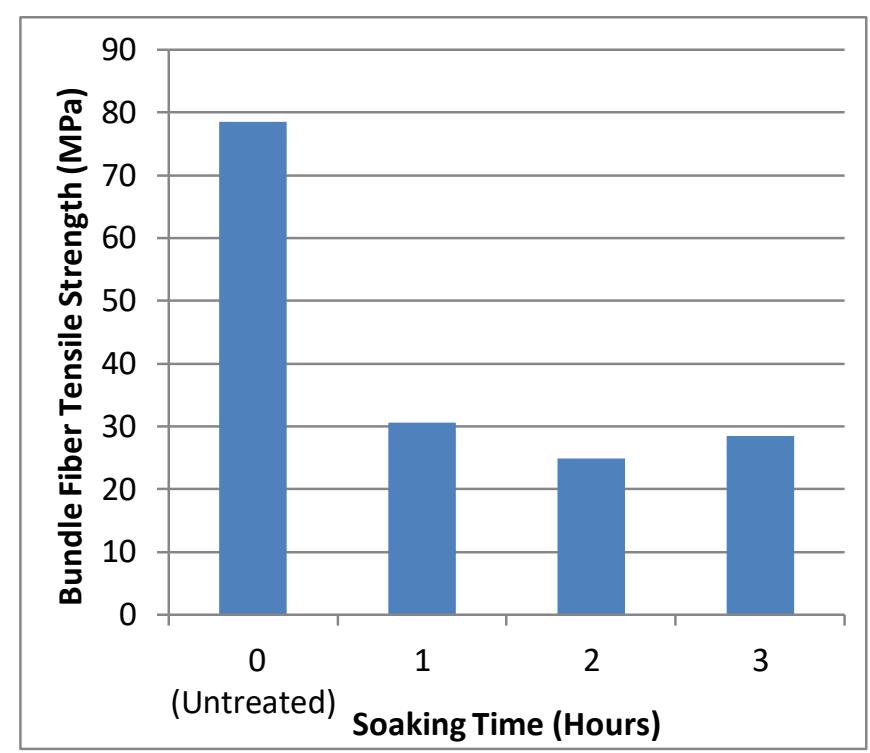

Fig. 4. Bundle Fiber Tensile Strength (MPa) of treated and untreated BFBF.

From Figure $2 \mathrm{a}$ and $2 \mathrm{~b}$, it is seen that as the soaking time increased, the tensile and impact strength also increased till it reached maximum strengths of $7.918 \mathrm{MPa}$ and $82.184 \mathrm{j} / \mathrm{m}^{2}$ at 3hours soaking time respectively. At first (1hour) treatment, the treated fiber might have experienced lower wettability due to the damaging effect of the treatment agent which caused some deterioration to the fiber particles themselves resulting in reduction of the strengths of the composite. (Setyanto et al., 2013) (Machaka, Abou Chakra and Elkordi Professor, 2014). As the treatment time increased, the fiber-matrix interpenetration became stronger with increased wettability, as the strengths further increased till maximum at 3hours optimum soaking treatment. However, from Figure $2 \mathrm{~b}$, the untreated $(84.421 \mathrm{j} / \mathrm{m})$ performed better than the treated, whereas from Figure 2a, the treated performed better than the untreated (7.204MPa).

The maximum flexural strength $(83.092 \mathrm{MPa})$ and modulus $(6416.547 \mathrm{MPa})$ as shown in Figure $3 \mathrm{a}$ and $3 \mathrm{~b}$ were obtained at optimum soaking time of 1 hour respectively. This increase in 1hour might be due to the alkali treatment attack, which removes the hemicellulose and lignin from fiber surface. Consequently, the properties elongation/maximum strain is improved, thus providing maximum properties at 1hour. (Sgriccia, Hawley and Misra, 2008) (Rosa et al., 2009) The maximum flexural strength and modulus yields better result than the untreated with $30.515 \mathrm{MPa}$ and $3708.506 \mathrm{MPa}$ respectively. 
The maximum BFTS (30.648MPa) as shown in Figure 4 was obtained at 1hour soaking time. This possibly could be at the point where the fiber experienced more fibrillation (fiber breaking) caused by alkali treatment, which helps to distribute the load applied throughout the fibers. Yet, at this maximum strength, the untreated fiber $(78.518 \mathrm{MPa})$ performed better than the treated.

B. Effect of soaking time on the physical properties of BFBF/Polyester composite.

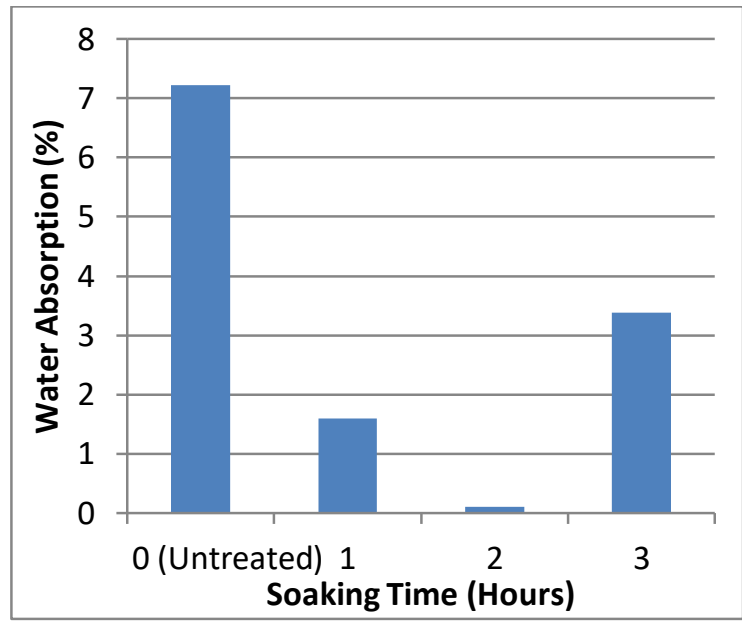

(a)

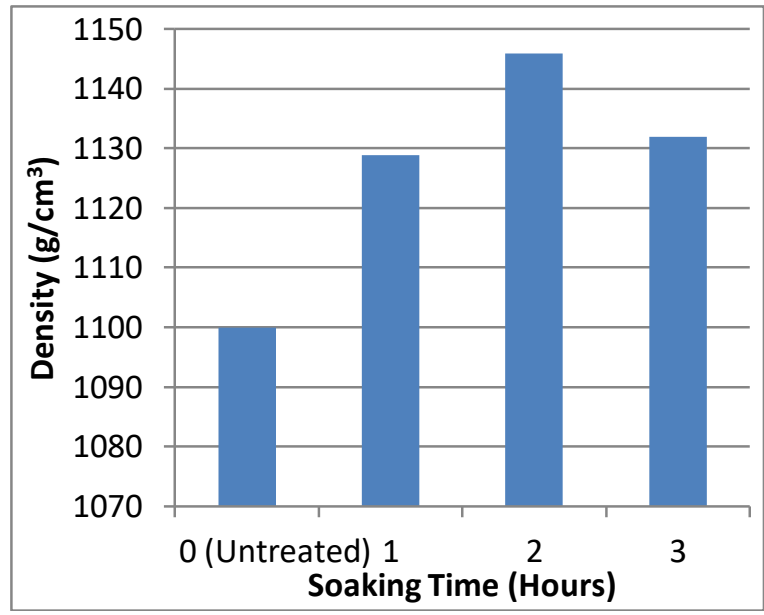

(b)

Fig. 5a. Percentage Water Absorption of treated and untreated BFBF Composites.

Fig. 5b. Density of treated and untreated BFBF composites.

As seen in Figure 5a, the maximum percentage water absorption $(3.379 \%)$ for the treated fiber composites was obtained at 3hours optimum soaking time. This might be due to more effect of the fiber treatment at 3hours, which exposed the fiber chemical properties as also seen in the tensile strength. This led to higher water absorption rate. The treated BFBF composite gave a better property than the untreated (7.216\%) since the untreated absorbed more water than the treated fibers. The maximum density $\left(1145.871 \mathrm{~g} / \mathrm{cm}^{3}\right)$ of the treated fiber composite was obtained at 2hours soaking time, while the minimum density occurred at 1hour soaking time, as shown in Figure $5 \mathrm{~b}$. The maximum density occurred possibly at the point where the attack of the treatment agent was strongest, which led to fibrillation and greater increase in density of the composite. At maximum density, the treated BFBF composite yielded a better result than the untreated $\left(1099.860 \mathrm{~g} / \mathrm{cm}^{3}\right)$ composite.

\section{SEM Analysis of Banana Fruit Bunch Fiber Polyester composite.}

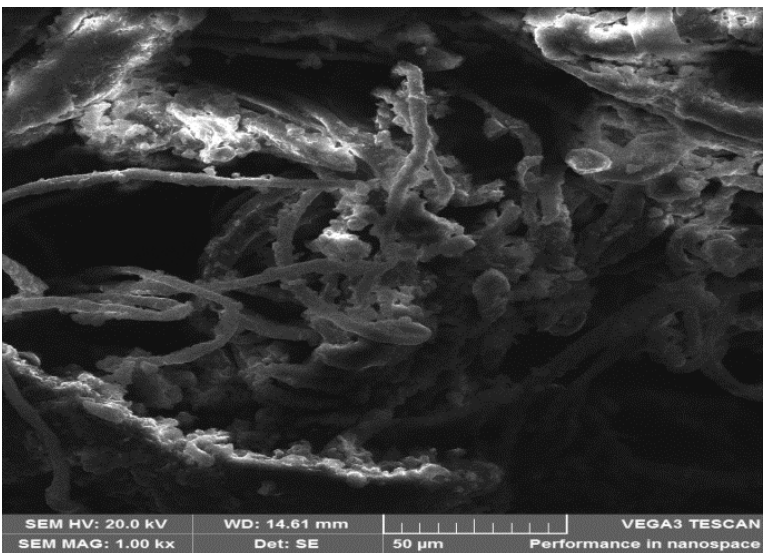

(a)

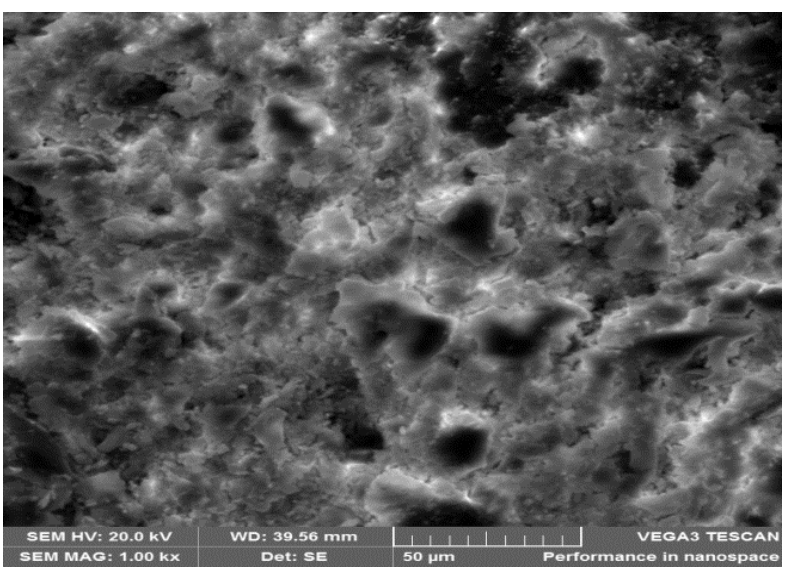

(b)

Fig. 6a. SEM of fractured surface of 3Hours treated BFBF composite. 
Fig. 6b. SEM of fractured surface of untreated BFBF composite.

Figure 6 showed the SEM micrograph of the untreated and treated fiber composites with best strength property. The treated BFBF composite (Figure 6a) showed a better surface than the untreated composite (Figure 6b), as also seen in the tensile strength test of the composite. This may be due to a better uniform distribution of the treated than the untreated during the matting stage prior to composite development, which leads to a better cross-sectional distribution of the treated on the polyester resin. It may also be due to the removal of the surface impurities and cementing materials like lignin and hemicellulose which leads to the increase in effective surface area of the fiber so it becomes more compatible with the matrix. This in turn resulted to a better fiber-matrix adhesion. Figure.6b showed a rougher surface than Figure 6a possibly due to twisting of the fiber into each other either during the development of the composite or during the curing/post-curing process. Hence the result of the treated showed a better surface than the untreated as also confirmed from the tensile strength test. The fracture mechanism associated to this micrograph is brittle fracture mechanism.

\section{The Thermogravimetric Analysis / Differential Thermal Analysis (TGA/DTA) of Banana fiber polyester composite.}

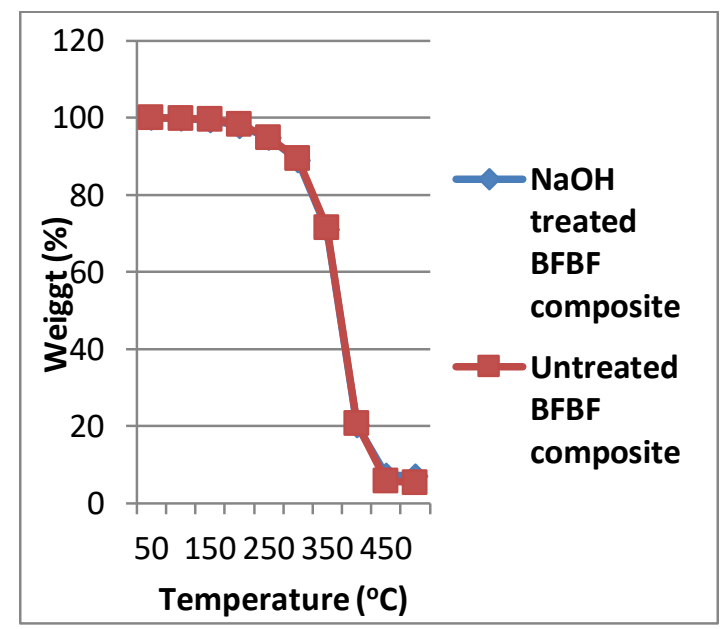

Fig. 7a. TGA of the 3 Hours $\mathrm{NaOH}$ treated and untreated BFBF polyester composites.

Figure 7a showed the Thermo-Gravimetric Analysis results of the treated and untreated BFBF composites with maximum strength property results. From the Figure, it can be seen that the overall change in weight loss occurred between the $50^{\circ} \mathrm{C}$ and $450^{\circ} \mathrm{C}$.
The specimen decomposed in three stages. The major decomposition occurred in the third stage (between $300-450^{\circ} \mathrm{C}$ ), the first decomposition occurred between $50-150^{\circ} \mathrm{C}$ while the second decomposition occurred between $150-300^{\circ} \mathrm{C}$. The first stage corresponds to the initial weight loss due to loss of moisture or solvents attached to the fiber and results in about $10 \%$ weight loss of the specimens. The second decomposition, between $150^{\circ} \mathrm{C}$ and $300^{\circ} \mathrm{C}$, corresponds to the hemicellulose decomposition and also results in about $15 \%$ weight loss. At the third stage, the major weight loss occurred at temperature between $300^{\circ} \mathrm{C}$ and $450^{\circ} \mathrm{C}$ due to decomposition of the crystalline cellulose, which then results in about $70 \%$ loss of specimens' weight. The final weight loss, though insignificant since it doesn't constitute the useful life of the fiber, occurred at temperature between $450-500^{\circ} \mathrm{C}$ due to decomposition of the lignin content of the fibers. Thus, the TGA results showed increase in the thermal stability of the fiber composites, and as such can be used to process engineering materials of temperature not more than $450^{\circ} \mathrm{C}$.

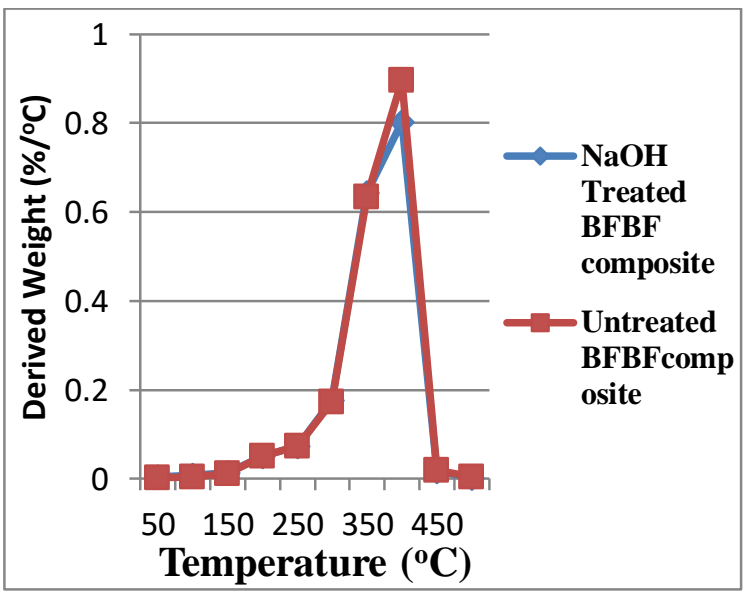

Fig. 7b. DTA of 3Hours $\mathrm{NaOH}$ treated and untreated BFBF polyester composites.

The Differential Thermal Analysis (DTA) was analyzed to determine the difference in thermal degradation of the fiber composite. From the Figure $7 \mathrm{~b}$, it can be seen that the first degradation, i.e. the initial decomposition temperature, occurred at a temperature of $50^{\circ} \mathrm{C}-150^{\circ} \mathrm{C}$, due to loss of moisture or solvents attached to the fiber. The second decomposition occurred at temperature between $150^{\circ} \mathrm{C}$ and $300^{\circ} \mathrm{C}$, corresponding to the hemicellulose decomposition. At the third stage, the major weight loss due to decomposition of the crystalline cellulose occurred at temperature between $300^{\circ} \mathrm{C}$ and $450^{\circ} \mathrm{C}$. The final weight loss, though insignificant since it 
doesn't constitute the useful life of the fiber, occurred at temperature between 450 and $500^{\circ} \mathrm{C}$ due to decomposition of the lignin content of the fibers. The DTA results also gave an improved thermal stability, thus the material can be used to produce engineering components of temperature between $50^{\circ} \mathrm{C}-450^{\circ} \mathrm{C}$, as also seen in the TGA results.

\section{E. The X-Ray Diffraction (XRD) Analysis of Banana fiber polyester composite}

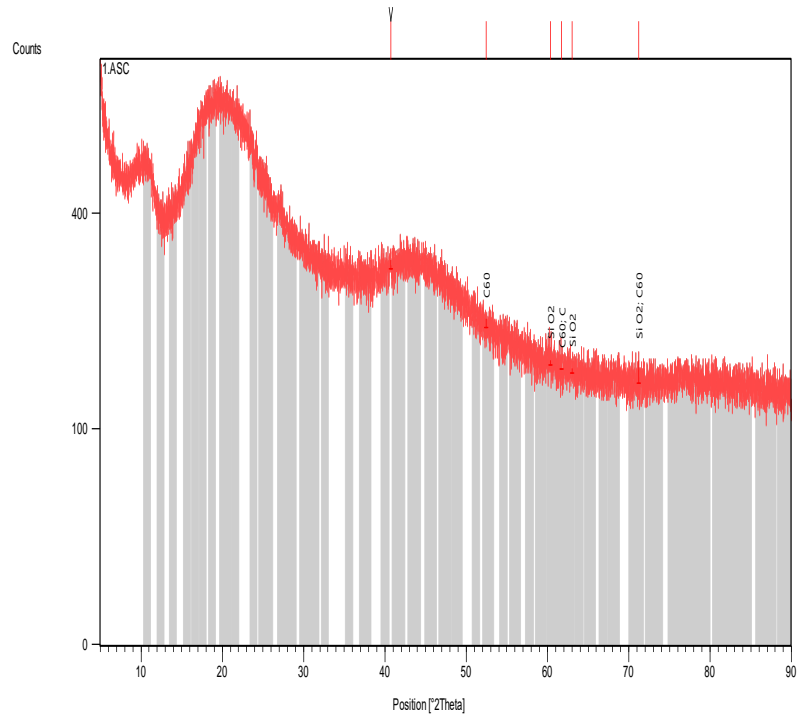

Fig. 8. XRD analysis of untreated BFBF polyester composite.

$\mathrm{XRD}$ analysis as shown in Figure 8 was performed on X-ray diffractometer which gave the crystalline and amorphous intensities at $2 \theta$ scale. The percentage crystallinity (\%Cr.) and crystalline index (C.I.) was determined using equation.3.3. From this Figure, it was shown that the untreated BFBF composite gave the amorphous intensity $\left(\mathrm{I}_{18}\right)$ between $16^{0}$ and $18^{0}$ $\left(16^{0} \leq 2 \theta \leq 18^{0}\right)$ at $2 \theta$ scale to be 600 and the crystalline intensity $\left(\mathrm{I}_{22}\right)$ between $21^{0}$ and $26^{0}\left(21^{0} \leq 2 \theta \leq 26^{\circ}\right)$ is 630 , while the percentage crystallinity (\%Cr.) and crystalline index (C.I.) is $51.22 \%$ and 0.05 respectively. This showed that the untreated has greater crystalline percentage.

\section{CONCLUSION}

This research was carried out to aid validate the effect of Alkali soaking time on the mechanical and physical properties of Banana Fruit Bunch Fiber (peduncle) reinforced polyester composite, with variation in soaking time of $1-3$ hours. The method used for composite preparation is Hand Lay-up method. From the results, it was deduced that;

1. The tensile strength of the treated fiber improved from $7.204 \mathrm{MPa}$ to $7.918 \mathrm{MPa}$ at 3hours optimum soaking time.

2. The flexural strength of the treated fiber improved from $30.515 \mathrm{MPa}$ to 83.092MPa at 1hour.

3. The flexural modulus of the treated fiber improved from $3708.506 \mathrm{MPa}$ to $6416.547 \mathrm{MPa}$ at 1 hour.

4. The impact strength of the treated fiber reduced to $82.184 \mathrm{j} / \mathrm{m}^{2}$ at 3hours, as the untreated gave $84.421 \mathrm{j} / \mathrm{m}^{2}$.

5. The Bundle Fiber Tensile Strength of the treated fiber also reduced to $30.648 \mathrm{MPa}$ at 3 hours and the untreated was $78.518 \mathrm{MPa}$.

6. The percentage water absorption of the treated fiber improved from $1.455 \%$ to $3.379 \%$ at 3hours.

7. The maximum density of the treated composite was obtained at 2 hours.

8. The density of the treated fiber improved from $1099.860 \mathrm{~g} / \mathrm{cm}^{3}$ to $1145.871 \mathrm{~g} / \mathrm{cm}^{3}$ at 2 hours.

The SEM result showed a better fibermatrix surface adhesion of the treated fiber composite than the untreated. The TGA/DTA results showed an improved thermal stability. The XRD of the untreated fibers obtained greater percentage of crystalline. It can therefore be seen that the sodium hydroxide treatment of Banana Fruit Bunch Fiber mostly improved the property of the composite at various optimum soaking time. Thus, the composites might be suitable for singleuse materials that require low strength.

\section{ACKNOWLEDGEMENT}

The authors first appreciate the Almighty God for wisdom and strength. We also thank the laboratory technologists of the department of Metallurgical and Materials Enginering, University of Nigeria nsukka, especially the chief technologist Engr. Cyril Ocheri, for all their tireless effort during this experiment.

They also express their gratitude to the entire staff of Mechanical Engineering Department, University of Nigeria Nsukka for their assistance during this work. 


\section{REFERENCES}

1. Arifuzzaman Khan, G. M. et al. (2013) 'Influence of chemical treatment on the properties of banana stem fiber and banana stem fiber/coir hybrid fiber reinforced maleic anhydride grafted polypropylene/low-density polyethylene composites', Journal of Applied Polymer Science, 128(2), pp. 1020-1029. doi: 10.1002/app.38197.

2. Campbell, F. (2010) 'Structural Composite Materials.', ASM International, p. 612.

3. Edwards, W. (2014) 'How Is the Buoyancy of an Object Affected by Different Liquids?', in, p. 2014.

4. Eng, C. C. et al. (2014) 'Impact strength and flexural properties enhancement of methacrylate silane treated oil palm mesocarp fiber reinforced biodegradable hybrid composites', Scientific World Journal, 2014. doi: 10.1155/2014/213180.

5. Ezema, I. C. et al. (2012) 'Ply Tensile Properties of Banana Stem and Banana Bunch Fibres Reinforced Natural Rubber Composite', 31(1), pp. 25-30.

6. J. Santhosh et al. (2014) 'Study of Properties of Banana Fiber Reinforced Composites', International Journal of Research in Engineering and Technology, 3(11), pp. 144-150.

7. Joseph, S., Koshy, P. and Thomas, S. (2005) 'The role of interfacial interactions on the mechanical properties of banana fibre reinforced phenol formaldehyde composites', Composite Interfaces, 12(6), pp. 581-600. doi: 10.1163/1568554054915183.

8. K. Kaushik, V., Kumar, A. and Kalia, S. (2013) 'Effect of Mercerization and Benzoyl Peroxide Treatment on Morphology, Thermal Stability and Crystallinity of Sisal Fibers', International Journal of Textile Science, 1(6), pp. 101-105. doi: 10.5923/j.textile.20120106.07.

9. Machaka, M., Abou Chakra, H. and Elkordi Professor, A. (2014) 'Alkali Treatment of Fan Palm Natural Fibers for Use in Fiber Reinforced Concrete', European Scientific Journal, 10(12), pp. 1857-7881.

10. Murli, D. and T. and Harris (no date) 'How to Prepare a Sodium Hydroxide Solution'.

11. Pilato, Louis A., Michno, M. J. (no date) 'Advanced Composite Materials', pp. 1-58. doi: 10.1007/978-3-662-35356-1.
12. Rosa, M. F. et al. (2009) 'Effect of fiber treatments on tensile and thermal properties of starch/ethylene vinyl alcohol copolymers/coir biocomposites', Bioresource Technology. doi: 10.1016/j.biortech.2009.03.085.

13. Setyanto, R. H. et al. (2013) 'A Preliminary Study: The Influence of Alkali Treatment on Physical and Mechanical Properties of Coir Fiber', 2(4), pp. 80-88. doi: 10.5539/jmsr.v2n4p80.

14. Sgriccia, N., Hawley, M. C. and Misra, M. (2008) 'Composites: Part A Characterization of natural fiber surfaces and natural fiber composites', 39, pp. 16321637. doi: 10.1016/j.compositesa.2008.07.007.

15. Sood, M. and Dwivedi, G. (2018) 'Effect of fiber treatment on flexural properties of natural fiber reinforced composites: A review', Egyptian Journal of Petroleum. Egyptian Petroleum Research Institute. doi: 10.1016/j.ejpe.2017.11.005. 